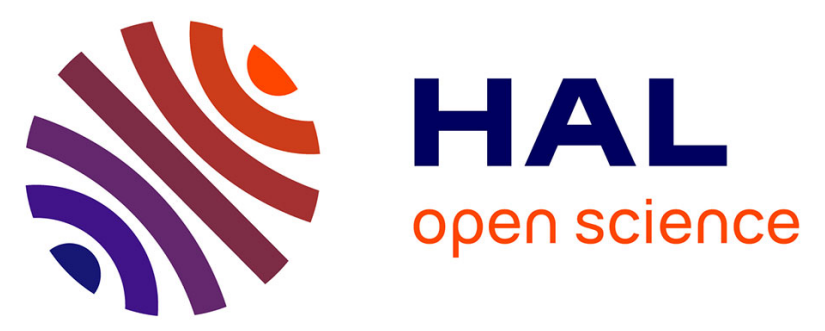

\title{
Application of the Data from Landsat8 OLI - The New Generation of Landsat Series in the Cultivated Land Information Extraction
}

\author{
Luyan Niu, Taichang Cui, Jiabo Sun, Xiaoyan Zhang
}

\section{To cite this version:}

Luyan Niu, Taichang Cui, Jiabo Sun, Xiaoyan Zhang. Application of the Data from Landsat8 OLI - The New Generation of Landsat Series in the Cultivated Land Information Extraction. 10th International Conference on Computer and Computing Technologies in Agriculture (CCTA), Oct 2016, Dongying, China. pp.52-63, 10.1007/978-3-030-06155-5_6 . hal-02180008

\section{HAL Id: hal-02180008 https://hal.inria.fr/hal-02180008}

Submitted on 12 Jul 2019

HAL is a multi-disciplinary open access archive for the deposit and dissemination of scientific research documents, whether they are published or not. The documents may come from teaching and research institutions in France or abroad, or from public or private research centers.
L'archive ouverte pluridisciplinaire HAL, est destinée au dépôt et à la diffusion de documents scientifiques de niveau recherche, publiés ou non, émanant des établissements d'enseignement et de recherche français ou étrangers, des laboratoires publics ou privés. 


\title{
Application of the Data from Landsat8 OLI - the New Generation of Landsat Series in the Cultivated Land Information Extraction
}

\author{
Luyan NIU (ORCID:0000-0002-6167-9569) ${ }^{1(凶)}$, Taichang CUI ${ }^{1}$, Jiabo SUN ${ }^{1}$, Xiaoyan ZHANG ${ }^{1}$ \\ ${ }^{1}$ Institute of Science and Technology Information, Shandong Academy of Agricultural Sciences Research, Jinan, \\ Shandong Province 250100, China \\ nly83412@126.com
}

\begin{abstract}
By making use of the image data of Landsat8 OLI newly launched by the United States and taking Liaocheng, Shandong Province as an example, we conduct computer correction and enhancement for the remote sensing image data of Liaocheng through the adoption of ENVI (a remote sensing image processing software) to extract information of cultivated land with the methods of visual interpretation, supervised classification and unsupervised classification. The result shows that based on the combination of Band5, 4, 3 and Band6, 5, 2 of Landsat8 OLI data, a relatively satisfactory cultivated land information can be acquired through visual interpretation, interactive methods of supervised classification and unsupervised classification.
\end{abstract}

Key words: Landsat8 OLI; Cultivated land; Classification ; Information abstraction

\section{Introduction}

Cultivated land is a fundamental resource which is essential to the survival of mankind, but in recent years, with the increase of the nation's population and the development of the national economy, the agricultural acreage keeps on reduction gradually, which has posed threats to agricultural development and people's basic livelihood. Therefore, it has become the main content of protecting arable land to conduct dynamic monitoring on the cultivated land, prevent degradation of the quality of it and maintain the dynamic balance of the total cultivated land.

Since the space distribution, quality and quantitative characteristics of the cultivated land resource vary with extreme dynamism as time goes by, it is rather difficult to acquire the actual information of cultivated land resource in real time through conventional field investigation technology.

However, remote sensing information, less affected by human factors, can truly reflect the objective reality of ground features and the nature of such data. Meanwhile, remote sensing is of high timeliness as the generation of information (such as the acquisition of production data and crop area) mainly relies on indoor operation, which works out the result very fast. Compared with other information collection ways, remote sensing also reduces the cost substantially for less dependence on numerous human and financial resources. What's more, remote sensing information has the advantages of abundant data, large cover area and short detection cycle as well as the continuity in time and space, thus the remote sensing information can be conducted with comparative analysis in time and space. Under the current market economy, it is of vital significance for precise estimation and mastery of the dynamic changes of crop yields to acquire the information of planting space and area of regional crops timely and accurately[1-2]. However, the information extraction of cultivated land remains one of the difficulties in the subject of remote sensing information extraction [3-4]. 


\section{Overview of Research Area}

Liaocheng, at the backland of the Central Plains and the west of Shangdong Province, close to Henan and Hebei provinces, is located at the junction (east longitude being at $115^{\circ} 16^{\prime}-116^{\circ} 32^{\prime}$ and north latitude being at $35^{\circ} 47^{\prime}-37^{\circ} 02^{\prime}$ ) of three major regions- the Eastern, Central and Northern China. The territory inside the border is relatively flat, basically being alluvial plain of the Yellow River except the 10 incomplete denuded mountains along the River in Dong'e County. Winter wheat, corn and cotton are the main crops grown here.

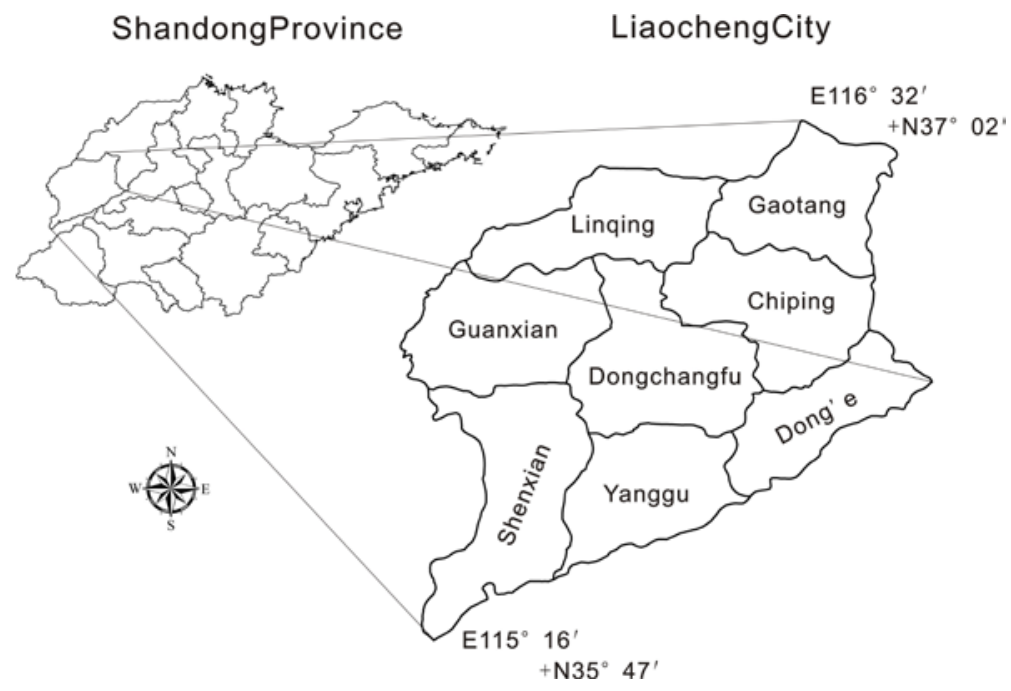

Fig. 1. Location of the study area

\section{Data Preparation}

\subsection{Introduction of Landsat8 OLI Data}

On February 11, 2013, Landsat8 was successfully launched in California, the US [5]. And on March 18, it obtained the first remote sensing image which was available for user downloading as sample data on $29^{\text {th }}$ of the same month [6].

Landsat-8 goes around the earth on the sun-synchronous orbit close to the polar, with orbit altitude at $705 \mathrm{~km}$ and orbit inclination at $98.2^{\circ}$. It circles around the earth once every 98.9 minutes and covers the earth once in 16 days. The descending node time was between 10 am local time to 10:15, with ADSL (Asymmetric Digital Subscriber Line) of satellite data at 441 Mbps.

The satellite carries with an OLI (Operational Land Imager) and a TIRS (Thermal Infrared Sensor) Along-track Imager. The OLI contains 9 short spectral bands, with the width at $185 \mathrm{~km}$, wherein ground resolution of panchromatic band is $15 \mathrm{~m}$ and that of other bands is $30 \mathrm{~m}$. Compared with the ETM sensor on Landsat-7, OLI has the following adjustments: OLI Band5 (0.845-0.885 um) excludes the water vapor absorption features at 0.825 um; the scope of OLI panchromatic Band8 is narrowed down so that the characteristics of areas with or without vegetation can be better distinguished on panchromatic images; besides, it is newly added with blue band (Band1:0.433-0.453um) for the observation of coastal zone and SWIR (short-wave infrared band) (Band9:1.360-1.390um) for cloud detection. 
Table 1. Technique parameters of Landsat8 sattellite OLI

\begin{tabular}{cccccccccc}
\hline Band No. & 1 & 2 & 3 & 4 & 5 & 6 & 7 & 8 & 9 \\
\hline Band & $\begin{array}{c}\text { Coasta } \\
\text { l/aeros }\end{array}$ & blue & green & red & NIR & SWIR & SWIR & pan & cirrus \\
& ol & & & & & 1 & 2 & & \\
& $0.43-0$ & $0.45-$ & $0.53-$ & $0.64-$ & $0.85-$ & $1.57-1$ & $2.11-2$ & $0.50-$ & $1.36-$ \\
Wavelength/um & .45 & 0.51 & 0.59 & 0.67 & 0.88 & .65 & .29 & 0.68 & 1.38 \\
& 30 & 30 & 30 & 30 & 30 & 30 & 30 & 15 & 30 \\
Spatial & & & & & & & & & \\
resolution/m & 12 & 12 & 12 & 12 & 12 & 12 & 12 & 12 & 12 \\
$\begin{array}{c}\text { Radiometr-ic } \\
\text { resolution /bit }\end{array}$ & & & & & & & & & \\
\hline
\end{tabular}

\subsection{Selection of Appropriate Bands}

The information extraction of various land use types is closely related to the cover of ground vegetation for land with different uses demonstrates distinct vegetation characteristics, thus bands selected should be those which can better reflect the green vegetation.

According to the need for extraction of crop cultivated area, bands with relatively higher sensitivity to crop information should be selected to highlight the different crop departments on image. In addition, based on the best visual effect principle, data from Landsat8 OLI has been conducted with comparative analysis on visual effects of different bands with reference to the brief introduction composed by OLI band published in foreign countries. The result shows that band5, 4, 3 and band6, 5, 2 perform better effect for the information extraction of cultivated land.

Table 2. Landsat8 OLI band synthesis of simple instructions

\begin{tabular}{|c|c|c|c|}
\hline R、G、B & Main uses & R、G、B & Main uses \\
\hline $4,3,2$ & Natural true color & $5,6 、 2$ & Healthy vegetation \\
\hline 7、6、 4 & City & $5,6 、 4$ & The land/water \\
\hline $5,4,3$ & $\begin{array}{c}\text { Standard false color, } \\
\text { vegetation }\end{array}$ & $7,5,3$ & $\begin{array}{l}\text { Natural surface to remove the } \\
\text { effects of the atmosphere }\end{array}$ \\
\hline $6 、 5,2$ & Agriculture & 7、5、4 & Short wave infrared \\
\hline 7、6、5 & Through the atmosphere & $6 、 5,4$ & Vegetation analysis \\
\hline
\end{tabular}

\subsection{Selection of Appropriate Time Phase}

The selection of an optimum time phase can not only intensify the obviousness of information of target crop and its relations with crop yield, weaken the interference from other factors at the same time, but also lower the uncertainty in remote sensing information and reduce the difficulty of information processing and correction[7].

Cultivated land mainly refers to land used for planting crops. According to the phonological characters of crop planting in Shandong Province and the analysis on the phonological calendars of all kinds of crops in the research area, it is believed that information extraction of cultivated land based on the spectral information of winter wheat is the most appropriate. In Northern China, the growth period of 
winter wheat is from September to next June, during which, most of the winter wheat planting area will go through a withering time. Therefore, the optimum time phase for extracting the cultivated land information is from mid-November to mid-December and early March to early April.

What are selected in this study are two images from Landsat8 OLI obtained on November 4, 2013, respectively marked as LC81230342013308LGN00 and LC81230352013308LGN00. Such images continue to use the projection/coordinate system of UTM/WGS84 of the Landsat series data. And processing format of the data is Level $1 \mathrm{~T}$, namely the geometric correction already conducted based on the topography. The two images can right cover the whole Liaocheng.

\subsection{Preprocessing of Landsat8 OLI Data}

The main purpose of preprocessing the remote sensing images is to eliminate irrelevant information contained in the images, recover the real useful information, enhance the detectability of relevant information and simplify the data maximally in order to improve the reliability of feature recognition and extraction[8].

The downloaded Landsat8 is level 1 product, whose data format is the classic TIFF, including 11 bands and image files, a quality evaluation file and metadata in a TXT file. The quality evaluation file mainly comprises operating environment parameters of the sensor while the metadata contain shooting time, solar altitude, longitude and altitude, etc. This study firstly carries out geometric correction on the data provided by Landsat8 OLI, and then insets the two images of Liaocheng to get the complete image covering the whole Liaocheng. And finally, generated data acquired through band synthesis, after being tailored to obtain the image of research area, will finally be fused with panchromatic band data so as to acquire an image with spatial resolution at $15 \mathrm{~m}$.

\section{Enhancement Processing of Landst8 OLI Remote Sensing Image}

\subsection{Band Synthesis}

Band combination can not only expand the diversity of ground features' bands, reflecting the dynamic scope demonstrated thereof, but also enhance the visibility observed by naked eyes to improve the recognition and interpretation of ground features for a much more scientific and reasonable result. As information extraction of cultivated land is closely related to the characters of ground coverage, considering the spectral characteristic of green vegetation, the image selected in this study is synthesized by Landsat8 OLI Band 5, 4, 3 (R, G, B), which, similar to color infrared image, is a standard false color image. With rich and distinct ground features and good gradations, it can be used for vegetation classification and recognition, vegetation displaying in red. And the image synthesized by Landsat8 OLI Band 6, 5, 2 (R, G, B) applies to agriculture which has relatively more vegetation types as it can intensify the information of bare land and distinguish it from the cultivated land. The synthesized images are as shown in picture 2 and 3 respectively: 


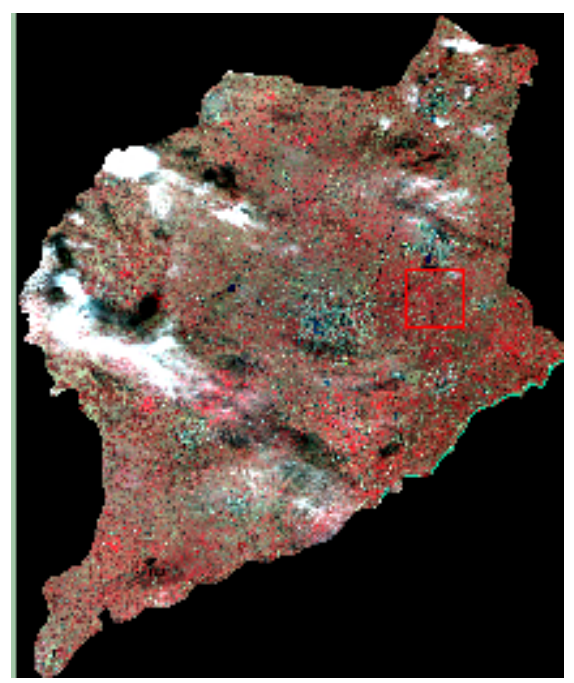

(a) Landsat8 OLI band 543 synthetic image

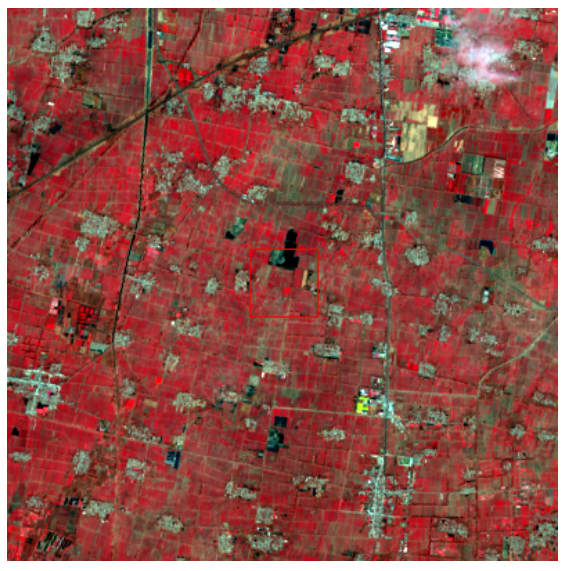

(b) Landsat8 OLI band 543 synthetic image local map

Fig. 2. Landsat8 OLI band 543 synthetic and synthetic image local map

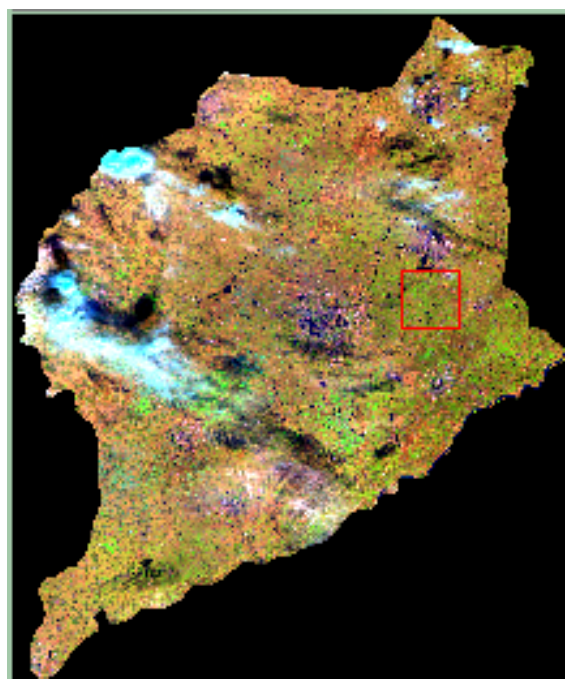

(a) Landsat8 OLI band 652 synthetic image 


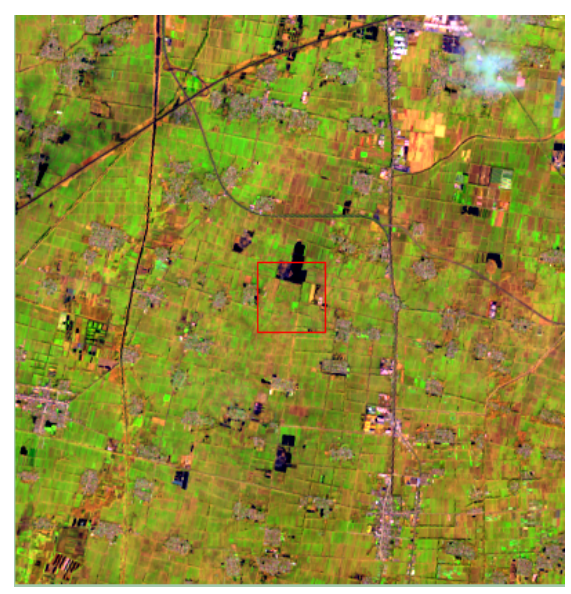

(b) Landsat8 OLI band 652 synthetic image local map

Fig. 3. Landsat8 OLI band 652 synthetic and synthetic image local map

\subsection{Contrast Enhancement}

This study adopts ENVI (The Environment for Visualizing Images) software to analyze the remote sensing image. When the said software opens an image, it will automatically conduct $2 \%$ linear enhancement processing within the system. The false color image generated by the processing is provided with clear gradations and distinct differences among ground features, thus it is much easier for recognizing the information of cultivated land.

\subsection{Image Fusion}

In order to acquire an image with the best visual effect for extracting the cultivated land information correctly, the image needs to be fused and intensified. As the spatial resolution of panchromatic Band8 in the data provided by Landsat8 OLI is $15 \mathrm{~m}$ and that of others is $30 \mathrm{~m}$, resample must be conducted to images with spatial resolution at $30 \mathrm{~m}$ in advance to achieve a resolution of $15 \mathrm{~m}$ so that images with two different resolutions can be fused. The images after being fused are as following picture 4 and 5 :

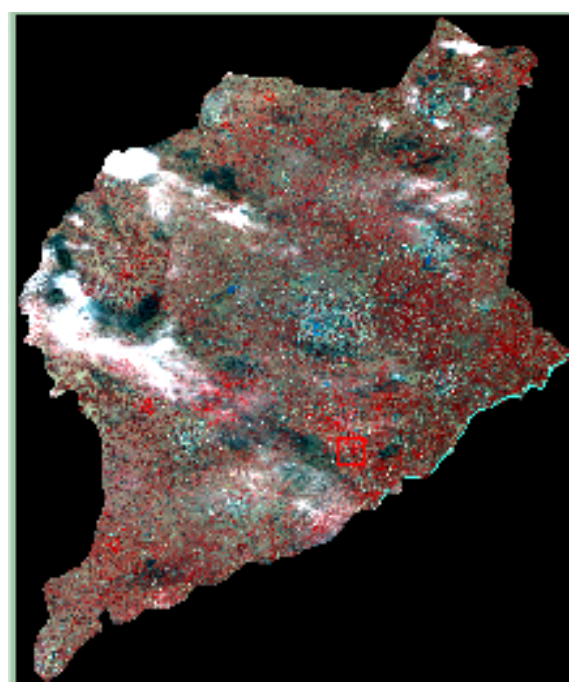

(a) Landsat8 OLI band 543 synthetic image and band8 panchromatic image after fusion 


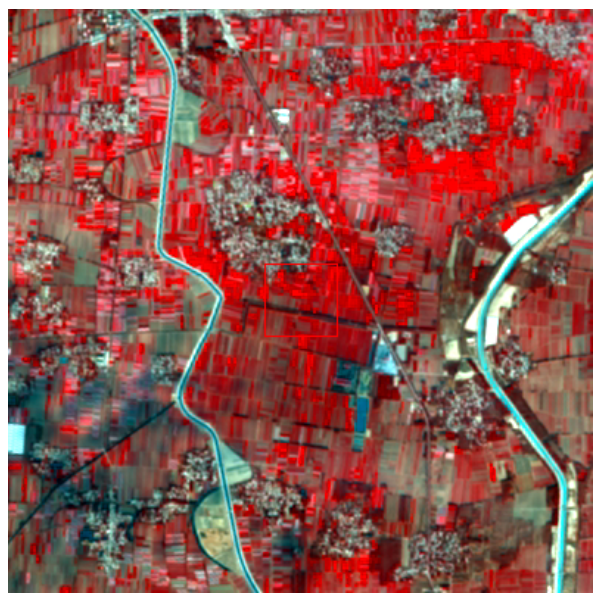

(b) Landsat8 OLI band 543 synthetic data and band8 panchromatic image after fusion of local mapimage local map

Fig. 4. Landsat8 OLI band 543 synthetic data and band8 panchromatic image after fusion and it's local mapimage local map

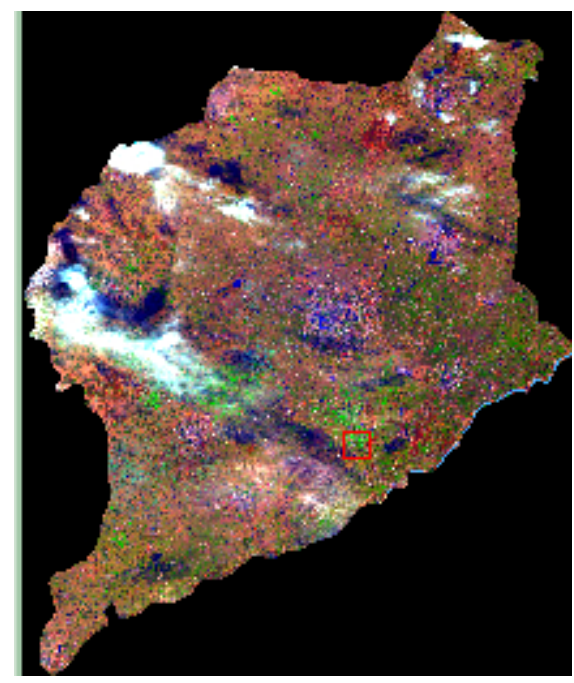

(a) Landsat8 OLI band 652 synthetic data and band8 panchromatic image after fusion

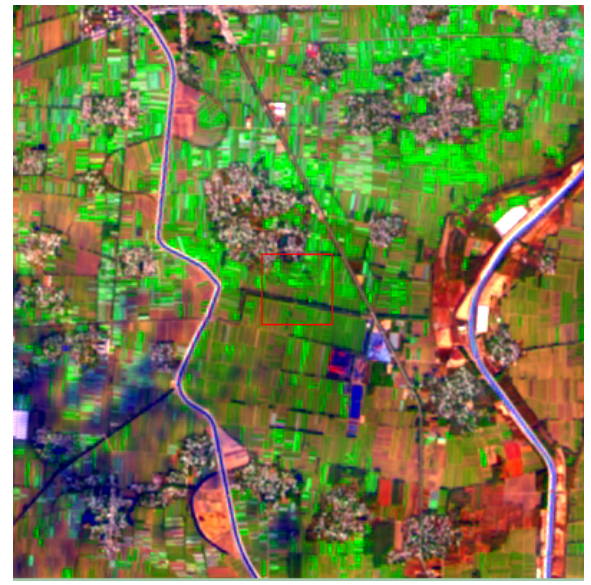

(b) Landsat8 OLI band652 synthetic data and band8 panchromatic image after fusion of local mapimage local map

Fig. 5. Landsat8 OLI band652synthetic data and band8 panchromatic image after fusion and it’s local mapimage local map 


\section{Information Extraction of Cultivated Land}

\subsection{Visual Interpretation}

The data provided by Landsat8 OLI are images with medium resolution. After going through data fusion, the spatial resolution can reach up to $15 \mathrm{~m}$. Hence, the exterior frames of many ground features can be seen clearly. Through interpretation marks, relevant geographical knowledge and extraction marks designated for resource information project, vector diagrams of cultivated land can be acquired after various characters on the image have been recognized, interpreted in classification and delineated on the screen. Although visual interpretation has a relatively high accuracy, it wastes a large amount of time and labor work.

\subsection{Unsupervised Classification}

According to the preliminary judgment of visual interpretation, ground features are divided into 9 categories, including cultivated land, forest land, naked land, waters, residential land, road land, unused land and other land, etc. During the actual process of classification, as cultivated land consists of multiple types featuring paddy field, irrigated land and dry land, etc, it shows different spectral characteristics of wheat field, naked sand and paddy field, etc. on the image. Therefore, it is better to adopt man-machine interactive unsupervised classification, through which we can set categories with relatively larger numbers and conduct gradual classifications to the result on the basis of comparing it with corresponding land detailed survey of current land use map. Those with the same classification can be merged together to reduce the number of categories until ideal classification are achieved ${ }^{[9]}$. This study introduces ISODATA (Iterative Self-organizing Data Analysis Techniques Algorithm) of ENVI unsupervised classification, which is to calculate the even-distributed class mean in data space and carry out iterated aggregation on the remaining pixels by using minimum distance technology. In each iteration, the mean is recalculated and the pixels are reclassified based on the new mean.

\subsection{Supervised Classification}

This study adopts SAM (Spectral Angle Mapper) in the supervised classification of ENVI. SAM, a kind of classification method based on physics, allocates pixels into corresponding sections through making comparison with the angles of terminal spectral vector and each pixel's vector in n-dimensional space. Smaller the angle is, more accurate the classification will be. In order to ensure the accuracy of the classification, before selecting samples, we need to conduct projection transformation, geometric correction, feature transformation and spectrum enhancement to the composite image by the bands of the data from Landsat8 OLI, and select the training region based on spectral characteristics of the cultivated land. The selection of the training region should proceed in the center with relatively larger area of the ground features.

\section{Accuracy Evalution}




\subsection{Accuracy Test of the Area}

By using the statistic tool provided by ENVI software, we can calculate the number of pixels the cultivated land of Liaocheng possesses, which will be multiplied by the actual size represented by each pixel. And the final extracted area of cultivated land is 523,973.69 hectares, with accuracy up to $92.6 \%$, compared with the detailed survey data.

\subsection{Accuracy Test of the Space}

Through the function of Classes Overlay provided by ENVI, after overlaying the distribution diagrams of cultivated land on the false color composite image synthesized by Band5, Band4 and Band 3 and the composite image of Band6, Band5 and Band2 respectively, we found that the extracted distribution of cultivated land is basically identical with the cultivated land information displayed on the image when comparing with the corresponding present land use map.

\section{Conclusions}

The data of Landsat8 OLI inherits the long-term earth observation ability of Lands at series and is an important remote sensing information source for ecological environment monitoring with its optimized observation ability. Based on it, favorable effect can be achieved through visual interpretation, and interactive methods of supervised classification and unsupervised classification. During the process of information extraction of cultivated land, the accuracy of classifications can be improved through combining the false color image synthesized by Band5, Band4 and Band3 of Landsat8 OLI data with the image synthesized by Band6, Band5 and Band2 which is specialized for agriculture and making contrast with the cultivated land information.

Therefore, it is feasible to conduct information extraction of cultivated land in cities and counties based on the data of Landsat8 OLI. Besides, the fast extraction speed and accurate result can meet the demand of acquiring the cultivated land information timely in land utilization and management.

Acknowledgement: gratitude is extended hereby for all the images shown in this article were downloaded from the website of USDS (United States Geological Survey).

\section{Acknowledgment}

Funds for this research was provided by the Special Public Welfare Industry(agriculture) Research project - Huang Huai Basin Wheat Corn Rice Field with Water Section Fertillizer Medicine Comprehensive Technology Solutions and Shandong Province Agriculture Major Application of Technology Innovation Project - Wheat Disease Early Information Quickly Identify Key Technology Research and Application。

\section{References}

1.QUARMBY N A,MILNES M,HINDLE T L, et al. The use of multi-temporal NDVI measurements from 
AVHRR data for crop yield estimation and prediction[J]. Internation journal of remote sensing,1993,14(2):199-210.

2.Fulu T,Masayuki Y,Zhao Z,et al.Remote sensing of crop production in China by production efficiency models:models comparisons,estimates and uncertainties[J].Ecological Modelling,2005,183(4):385-396.

3.DENG Jin-song, WANG Ke, SHEN Zhang-quan, etal . Decision t ree algorithm of automatically extracting $f$ armland information from SPOT $\square 5$ images based on characterist ic bands [J] .Transactions of the Chinese Society of Agricultural Engineering, 2004,20( 6) : 145 148.

4. Victor Mesev.The use of census dat a in urban imagine classif ication[ J] . Photogrammetric Engineering \& Remote Sensing , 1998, 64 ( 5) :431 438.

5. NASA.LDCMLaunch. http://www.nass.gov/mission_pages/landsat/launch/index.html.2013/4/18.

6.NASA.A Closer Look at LDCM's First

http://www.nasa.gov/mission_pageslandsat/news/first-images-feature. html.2013/4/18

7.Qian Huai-sui. Selection of the optimum temporal for cropestimation using remote sensing data: main food crops inChina[J]. Acta Ecologica Sinica, 1998, 18(1): 48-55. (inChinese with English abstract

8.WANG Yu-li, MA Zhen. Visual Interpretation TM Image Land Use Classification by Applied the Software of ENVI[J].Modern Surveving and Mapping,2011,34 (1): 11-13.

9.ZHAO Geng-xing, DOU Yi-xiang, TIAN Wen-xin, et al. Study on Automatic Abstraction Methods of Cultivated Land Information from Satellite Remote Sensing Images[J].SCIENTIA GEOGRAPHICA SINICA,2001,21(4):224-229. 